\title{
Onlay versus Sublay Mesh Repair in the Management of Uncomplicated Ventral Abdominal Wall Hernias
}

\author{
Yasser Hatata $^{(1)}$, Nadir Shaaban ${ }^{(1)}$, Tamer Al-Gaabari ${ }^{(1)}$, Mohamed Shaaban $^{(2)}$ \\ (1) MD, General surgery department, Fayoum University, Fayoum, Egypt. \\ (2) MSc, General surgery department, Fayoum University, Fayoum, Egypt.
}

Corresponding author: Dr. Mohamed Shaaban

Fax: +2084636583

Tel: 01025718596

\begin{abstract}
Aim of the study: The aim of the study is to compare between two techniques of mesh placement in uncomplicated ventral hernias, onlay versus sublay,comparing the operative technique,length of operation, the postoperative complications and recurrence.

Methods: Thirty patients with a defect size ranging from 3.5 to $15 \mathrm{~cm}$ were prospectively randomized into 2 groups: Group A ( $\mathrm{n}=15)$ was operated upon using the onlay mesh repair technique and group $\mathrm{B}$ $(n=15)$ was operated upon by means of the sublay mesh repair technique. The operative time, postoperative complications and short-term recurrence were reported.
\end{abstract}

Results: In this study, onlay placement of the mesh significantly reduced the operative time (which was longer in the sublay mesh group; $\mathrm{P}=$
0.007). Fewer incidences of seroma formation in the sublay group after drain removal (which was higher in the onlay mesh group) with no statistical significance ( $\mathrm{P}=0.7$ ). There were 3 events of Superficial surgical site infection (SSI) in the onlay group compared to only one event in the sublay group. Also one event of retro-rectus haematoma in the sublay group, skin flap necrosis occurred in one case of the onlay group with no statistical significance.

Conclusion:Both sublay and onlay mesh placement techniques for ventral hernia repairs in low-risk adults are safe, efficient and are associated with comparable complications rate. Additional studies are needed to determine the long term benefits of both approaches with respect to mesh infection rates and hernia recurrence rates.

KEYWORDS: Ventral hernias, Onlay, Sublay, Mesh, Recurrence, Repair.

\section{INTRODUCTION}

Ventral hernia is commonly encountered in surgical practice. An estimated one-quarter of all individuals are either born with or will develop a ventral hernia in their lifetimes [1]. It is a common surgical problem and refers to fascial defect of the anterolateral parietal abdominal wall fascia and muscles, through which intermittent or continuous protrusion of intra-abdominal or preperitoneal contents occurs [2].

These hernias have various types that can be categorized into either de novo or incisional; 
which occurs at the site of a pervious surgical scar. Both types have two subtypes, lateral and midline ventral hernias [3].

Despite advances in surgical technique and prosthetic technologies, the risks for recurrence and infection are high following the repair of ventral hernias. High-quality data suggest that all ventral hernia repairs should be reinforced with prosthetic repair materials.

The current standard for reinforced hernia repair is synthetic mesh, which can reduce the risk for recurrence in many patients. The most 2 positions for mesh application in open repair are the onlay repair where the mesh is positioned over the anterior rectus sheath, and the sublay (retromuscular) repair, the more commonly known as stoppa technique [4].

Permanent synthetic mesh can pose a serious clinical problem in the setting of infection $[5,6]$. However, it is the understanding of the abdominal wall that has made complex procedures possible including myofascial and musculocutaneous advancement flaps through component separation and muscular release [7]. These advancements have enabled surgeons the technical ability to use prosthetics in different manners and grant closure of abdominal defects that were considered impossible in the past. (7)

\section{Patients and Methods}

The study is prospective, comparative and randomized controlled trial. It includes 30 patients randomized into 2 equal groups. The patients were admitted from the outpatient clinic of Fayoum university hospitals, after being diagnosed with ventral abdominal wall hernia. All underwent open, elective ventral hernia repair using synthetic polypropylene mesh placement in the period from November 2017 to April 2018.

The patients were orally and officially consented using the standard form of the informed written consent form. The study was approved by the medical ethics committee of the Faculty of Medicine, Fayoum University.

Following preoperative evaluation and preparation for surgical intervention, the cases were randomized into 2 equal groups,

Group A: underwent the onlay mesh hernial repair (15 patients)

Group B: underwent the sublay (retromuscular) mesh hernial repair (15 patients)

The patients had to fulfill the following inclusion criteria: they had to have no other serious diseases, including hemorrhagic disorders; they had to have uncomplicated ventral hernias and agreed to undergo surgery following either onlay mesh repair or sublay (retromuscular) mesh repair. The exclusion criteria were the extremes of age, having inflamed, obstructed, recurrent, or strangulated ventral hernias and very large ventral hernia defects that need special consideration before surgical interference.

Full clinical history was recorded with special attention to age, occupation, and special habits (drug abuse and/or smoking). Examination of the considering site of the hernia, size of the defect, numbers of the defects, irreducibility, impulse on coughing, tenderness and intestinal sound.

Routine laboratory investigations were done for all patients including complete blood count (CBC), ALT, AST, Urea, Creatinine, serum albumin, P.T and blood sugar (HBA1c will be done in diabetic patient and interpreted as below 7 $\mathrm{mg} \%$ : controlled diabetes, above $7 \mathrm{mg} \%$ : uncontrolled diabetes).

Radiological investigations such as abdominal ultrasonography to exclude any intra-abdominal concurrent pathology. ECG, and plain chest radiography in case of previous history of smoking, bronchial asthma, or clinical signs of chest troubles.

All patients of both groups received prophylactic antibiotic treatment before surgical incision.

General or spinal anesthesia was used. All patients were placed in the supine position. Operative field 
was sterilized by povidone-iodine and toweled up in normal manner.

The operative technique included the following steps: In the onlay repair group an incision is made in the groove above or below the hernia. If necessary, extend the cut transversely outwards on each side, but for incisional ventral hernias skin incision is done removing the old scar and just equal to the size of the defect.

Then the incision is deepened to identify the aponeurosis and expose it around the adjacent half of the circumference of the hernia. Expose $2 \mathrm{~cm}$ of aponeurosis around the remainder of the margin of the hernia. Cut through the thinned-out edge of aponeurosis to expose the peritoneum and gradually work round to display the whole circumference of the neck of the sac. Clear the sac of fatty tissue and cut it right round, at least $2 \mathrm{~cm}$ distal to the neck if possible.

The contents of the sac are less likely to be adherent here than in the fundus, but free them if necessary. Mark the peritoneal edges with artery forceps. If the contents of the sac are free, reduce them. If they are adherent to the fundus of the sac, free them and return them to the peritoneal cavity. If there is a mass of fibrous omentum, excise it with the fundus of the sac but take care to ligate all the bleeding omental vessels and avoid damaging the transverse colon.

After reducing the hernia and lysis of adhesions, the hernia defect is closed in a continuous fashion using 2/0 polypropylene suture material and skin flaps are raised exceeding the semilunar line.

A macroporous, light weight polypropylene mesh is positioned in an onlay manner covering the entire area of exposed fascia and any external releases. The mesh was stretched over the whole dissected abdominal aponeurosis until 5-7 cm [8] around the defect and was fixed to the anterior rectus sheath with a polypropylene $2 / 0$ suture Figure (1). The sutures were taken with good bites of the aponeurosis and the mesh. Multiple scattered simple sutures were used for fixation of the mesh. A vacuum drain is placed in front of the mesh, as this procedure with its undermining of the skin and placement of a foreign body is at risk of seroma formation.

Regarding the sublay (retromuscular) repair group, the operation typically begins with a midline incision. The hernia sac is divided in the midline and the peritoneum is incised. This allows the visceral contents to be fully explored and any additional operations can be performed. Lysis of adhesions from the abdominal wall was done, as it helps with the mobility for closing the peritoneum and posterior rectus sheath in the midline.

Next, after incising the rectus sheath along the whole length of the incision, the dissection of the posterior rectus sheath is then advanced cranial and caudal to the hernia defect for a minimum distance of 5-8 cm [8]. The posterior rectus sheath is fused to the linea alba at its lateral most aspect. The posterior sheath is separated from the linea alba at its lateral aspect to create a space for mesh placement crossing the midline behind the rectus muscles above and below the hernia defect. Dividing the posterior sheath off of the lateral most portion of the linea alba is a crucial step so as to preserve the linea alba making it the midline thrust bearing portion of the abdominal wall anterior to the mesh above and below the hernia figure (2).

The dissection is performed bluntly either with finger or sponge dissection, or otherwise with cautery. During this retrorectus dissection, the inferior epigastric vessels as well as the segmental innervation of the rectus muscle should be anticipated and preserved.

If the hernial defect reached the upper abdomen, we may need to continue dissection up to the costal margin and behind the xiphoid process. For hernias extending below the umbilicus, the surgeon will need to preserve fascia transversalis, preperitoneal fat and peritoneum in order to have tissue for closure of the visceral sac. The dissection could be extended into the preperitoneal 
spaces of Retzius and Bogros, to expose the pubic bone, ligament of Cooper, and the iliac vessels on both sides.

The posterior rectus sheath is approximated in the midline once the dissection is complete using size 2-0, non-absorbable polypropylene suture material in a continuous fashion. Closure could be aided at this stage by a portion of the hernia sac which was preserved and still attached. A horizontal mattress fashion could be utilized if the running sutures caused tearing, the suture bites may be oriented to incorporate more tissue, thus adding strength.

It is very critical to close the posterior sheath completely preventing any bowel from slipping in between the posterior sheath and the mesh, which could result in an intestinal obstruction.

The retro-rectus space in then measured, and the mesh is trimmed and applied to occupy the entire space. After that the mesh should be fixed circumferentially with full-thickness non- absorbable polypropylene sutures through the abdominal wall. If it reaches the costal margin, the mesh is sutured into the costal margin after being placed below the ribs. Likewise, hernias extending into the low abdomen, the mesh is sutured into the Cooper's ligaments bilaterally and the pubic symphysis. The mesh should lay taut in this space as the space will become smaller once the rectus muscle is reapproximated overtop the mesh.

Ideally, the surgeon should avoid introducing wrinkles into the mesh as it decreases mesh-tissue area interface.

At the end of mesh placement, closed suction drain is placed, through separate stab incision, into the retro-muscular. The drains will directly rest on top of the mesh. The midline is now reconstructed by suture reapproximating the edges of the linea alba in a continuous fashion using a size 0 nonabsorbable polypropylene suture.

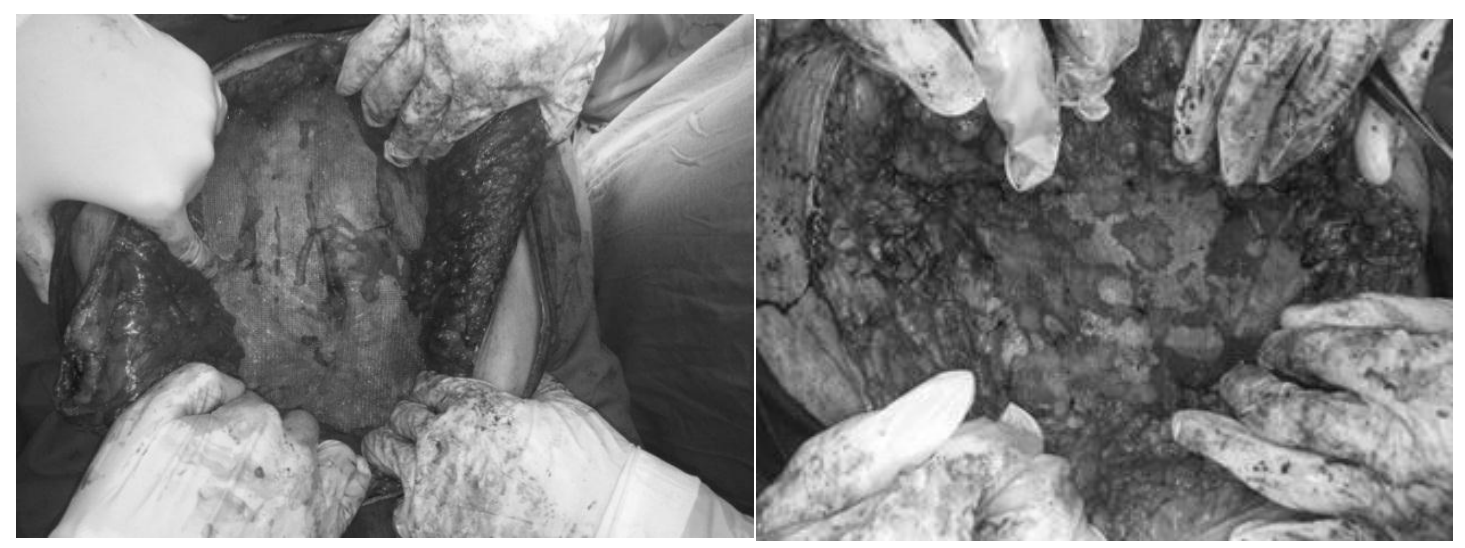

Fig (1): showing onlay mesh repair with fixation 


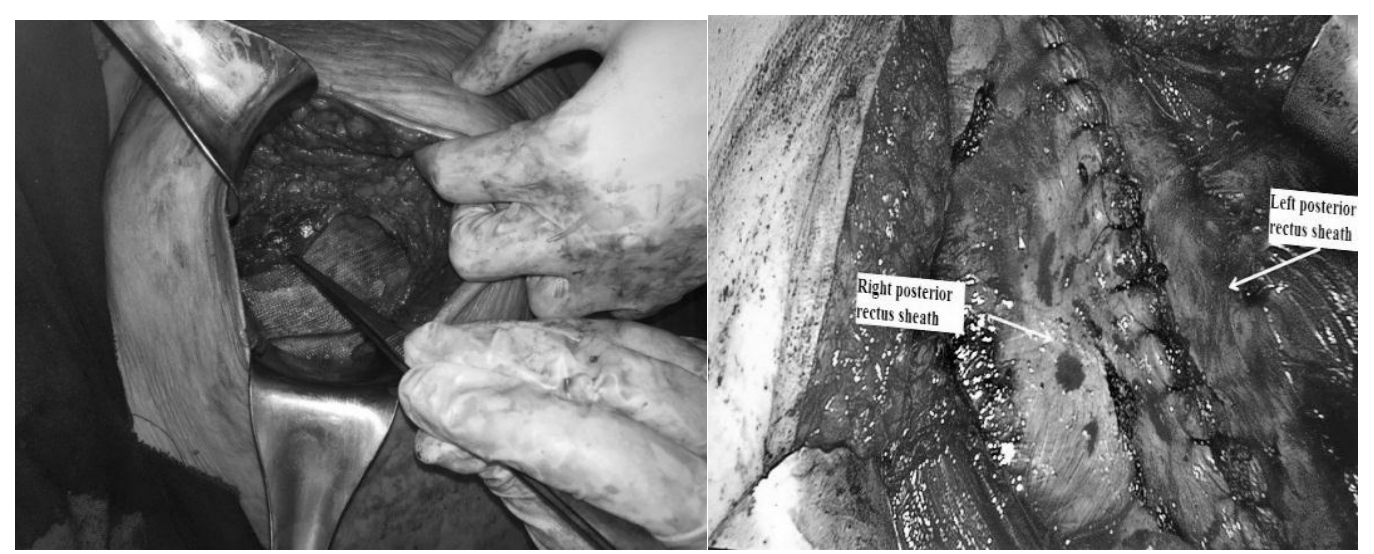

Fig(2) showing creation of space for sublay mesh placement and closure of posterior rectus sheath

\section{RESULTS}

Current study included 30 hernia patients fulfilling selection criteria and surgically managed with two mesh repair surgical techniques; onlay, with 15 patients, and sublay with 15 patients.

Out of 15 patients in group A, 11 were female (73.3\%) and 4 were male $(26.75 \%)$. Their ages ranged from 27 to 59 years (Mean 40.1), and BMI ranged from 23.7 to 33.5 (Mean 29.3). In group B, 10 were female (66.7\%) and 5 were male (33.3\%). Ages range from 19 to 45 years (Mean 33.8). BMI from 21.4 to 34 (Mean 27.4) illustrated in table 1. The different types of ventral hernias seen in this study are summarized in table 2 .

Table (1): Comparisons of demographic characters in different type of repair.

\begin{tabular}{|l|l|l|l|l|l|l|}
\hline Variables & $\begin{array}{c}\text { Group A } \\
\text { Onlay } \\
(\mathrm{n}=15)\end{array}$ & \multicolumn{1}{|c|}{$\begin{array}{c}\text { Group B } \\
\text { Sublay } \\
(\mathrm{n}=15)\end{array}$} & p-value & Sig. \\
\hline \multicolumn{7}{|c|}{ Mean /SD } \\
\hline Age (years) & 40.1 & 9.9 & 33.8 & 8.9 & 0.08 & NS \\
\hline BMI $\left(\mathrm{kg} / \mathrm{m}^{2}\right)$ & 29.3 & 3.2 & 27.4 & 4.1 & 0.2 & NS \\
\hline \multicolumn{7}{|c|}{ Sex } \\
\hline Male & 4 & 26.75 & 5 & $33.3 \%$ & \multirow{2}{*}{0.9} & NS \\
\hline Female & 11 & $73.3 \%$ & 10 & $66.7 \%$ & & \\
\hline
\end{tabular}

Table (2): Comparisons of hernia types in different type of repair.

\begin{tabular}{|c|c|c|c|c|c|c|}
\hline \multirow[t]{2}{*}{ Variables } & \multicolumn{2}{|c|}{$\begin{array}{c}\text { Group A } \\
\text { Onlay } \\
(n=15)\end{array}$} & \multicolumn{2}{|c|}{$\begin{array}{c}\text { Group B } \\
\text { Sublay } \\
(n=15)\end{array}$} & \multirow[t]{2}{*}{ p-value } & \multirow[t]{2}{*}{ Sig. } \\
\hline & No. & $\%$ & No. & $\%$ & & \\
\hline \multicolumn{7}{|c|}{ Type of hernia } \\
\hline Epigastric & 5 & $33.3 \%$ & 7 & $46.7 \%$ & 0.7 & NS \\
\hline
\end{tabular}




\begin{tabular}{|c|c|c|c|c|c|c|}
\hline Paraumbilical & 5 & $33.3 \%$ & 5 & $33.3 \%$ & & \\
\hline Incisional & 5 & $33.3 \%$ & 3 & $20 \%$ & & \\
\hline \multicolumn{7}{|c|}{ Type of incision } \\
\hline Midline & 1 & $20 \%$ & 1 & $33.3 \%$ & \multirow{5}{*}{0.6} & \multirow{5}{*}{$\mathrm{NS}$} \\
\hline Paramedian & 1 & $20 \%$ & 0 & $0 \%$ & & \\
\hline Pfennestiel & 2 & $40 \%$ & 1 & $33.3 \%$ & & \\
\hline Kocher & 1 & $20 \%$ & 0 & $0 \%$ & & \\
\hline Gridiron & 0 & $0 \%$ & 1 & $33.3 \%$ & & \\
\hline
\end{tabular}

The mean total time taken to perform surgery in the onlay group was 58.3 (SD 16.9) $\mathrm{min}$ compared with 75.7 (SD 15.6) min in the sublay group $(\mathrm{P}=0.007)$ which showed a highly significant difference. Suction drain was kept in all cases of onlay and sublay meshplasty.
Regarding the defect size in group A the mean was 6.7 (SD 3.1), and in group B was 5.1 (SD 1.4). Mean duration of hospital stay in the onlay group 2.5 days (SD 0.7), whereas it was 2.3 days $(\mathrm{SD} 0.8)$ in the sublay group $(\mathrm{P}=$ $0.6)$.

Table (3): Comparisons of operative characters in different type of repair.

\begin{tabular}{|r|l|l|l|l|l|l|}
\hline \multirow{2}{*}{ Variables } & \multicolumn{2}{|c|}{$\begin{array}{c}\text { Group A } \\
\text { Onlay } \\
(\mathrm{n}=15)\end{array}$} & \multicolumn{2}{c|}{$\begin{array}{c}\text { Group B } \\
\text { Sublay } \\
(\mathrm{n}=15)\end{array}$} & p-value & Sig. \\
\cline { 2 - 7 } & Mean & SD & Mean & SD & & \\
\hline Operation time (min) & 58.3 & 16.9 & 75.7 & 15.6 & $\mathbf{0 . 0 0 7}$ & HS \\
\hline Defect size (cm) & 6.7 & 3.1 & 5.1 & 1.4 & 0.09 & NS \\
\hline Hospital stay (day) & 2.5 & 0.7 & 2.3 & 0.8 & 0.6 & NS \\
\hline
\end{tabular}

In group A, two (13.3\%) patients In group A, superficial surgical site developed wound seroma with no events of haematoma formation unlike group B where there was no cases complicated seroma formation and only one event of retro-rectus haematoma $(6.7 \%)$. They were treated with repeated aspiration of the seroma under complete aseptic conditions. infection occurred in three $(20 \%)$ patients but in group B wound infection occurred only in one $(6.7 \%)$ patient $(\mathrm{P}=0.010)$; these patients were treated conservatively with broad-spectrum antibiotics. There was only a case of flap necrosis in group A (6.7\%), with no similar events in group B. 


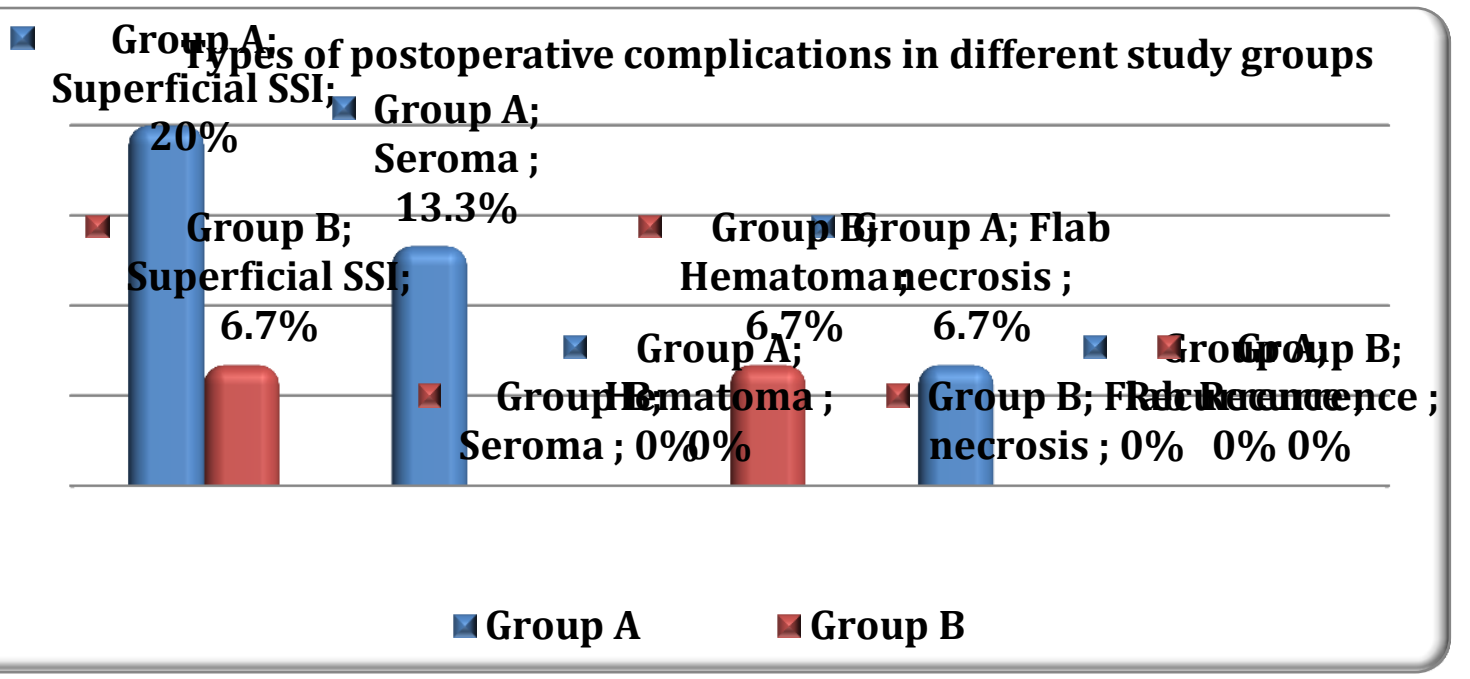

Table 4 illustrates the past history of cases regarding chronic health conditions ,smoking habits and substance abuse in both groups.

Table (4): Comparisons of special habit and chronic disease in different type of repair.

\begin{tabular}{|c|c|c|c|c|c|c|}
\hline \multirow[t]{2}{*}{ Variables } & \multicolumn{2}{|c|}{$\begin{array}{c}\text { Group A } \\
\text { Onlay } \\
(\mathrm{n}=15) \\
\end{array}$} & \multicolumn{2}{|c|}{$\begin{array}{c}\text { Group B } \\
\text { Sublay } \\
(\mathrm{n}=15) \\
\end{array}$} & \multirow[t]{2}{*}{ p-value } & \multirow[t]{2}{*}{ Sig. } \\
\hline & No. & $\%$ & No. & $\%$ & & \\
\hline \multicolumn{7}{|c|}{ Smoking } \\
\hline Non-smoker & 12 & $80 \%$ & 13 & $36.7 \%$ & \multirow{3}{*}{0.6} & \multirow{3}{*}{ NS } \\
\hline Smoker & 2 & $13.3 \%$ & 2 & $3.3 \%$ & & \\
\hline Substance abuse & 1 & $6.7 \%$ & 0 & $0 \%$ & & \\
\hline \multicolumn{7}{|c|}{ Chronic disease } \\
\hline $\mathrm{DM}$ & 2 & $40 \%$ & 4 & $80 \%$ & \multirow{3}{*}{0.3} & \multirow{3}{*}{ NS } \\
\hline HTN & 1 & $20 \%$ & 0 & $0 \%$ & & \\
\hline Bronchial asthma & 0 & $0 \%$ & 1 & $20 \%$ & & \\
\hline
\end{tabular}

\section{DISCUSSION}

Ventral hernia repair in adults is among the most commonly performed surgical operations worldwide. It includes both primary ventral hernias (true ventral- non-incisional hernias), which include two subtypes lateral ventral hernia and midline ventral hernias, and, more commonly, incisional hernias after an abdominal operation [9].

The incidence varies from 2 to $20 \%$ [10], with extreme values ranging from 0 to $91 \%$ [11] [12]. It

is estimated that $11 \%$ of all abdominal operations result in an incisional hernia [13].

Many surgical techniques were advocated; however, there is still doubt about the ideal and best method that provides the least incidence of recurrence rates and applies to the patient satisfaction. Local repair without the use of mesh could result in higher recurrence rates. Additionally, the abdominal wall might be more 
destroyed or weakened, making future attempts of repair more difficult.

Each ventral hernia has unique characteristics and particular patient comorbidities that mandate an individualized approach to balance the patients' and surgeons' goals with minimization of the postoperative morbidity and improvement of the long-term durability of the hernia repair.

Small hernial defects, less than $2.5 \mathrm{~cm}$ in diameter, are often successfully closed with local tissue repairs [14]. However, the larger ones, more than $2.5 \mathrm{~cm}$ in diameter, have a recurrence rate of up to $30-40 \%$ in case of performing the local tissue repair alone [15].

Hernia recurrence is both distressing to the patient and embarrassing to the surgeons. Nowadays, tension free repair; using prosthetic mesh, has reduced the recurrence rates to negligible values [9]. Despite excellent results, increased risks of infection with placement of a foreign body; the prosthetic mesh, and cost-related factors still exists [16]. However, both of operative time and duration of hospital stay are shortened. The local tissue repair is associated with higher recurrence rates. Nowadays, tension free mesh repair is widely accepted as the most attractive hernia repair technique [17].

Nevertheless, the current literatures provide little definitive guidance, with the risk of wound events and hernia recurrence rates varying considerably in the literature, with estimates as high as $75 \%$ $[18,19,20,21]$. Despite, the use of mesh during VHR is universally accepted as a method to help to reduce the potentiality for hernia recurrence, additional efforts are needed to address patient and operative factors that affect wound events and VHR durability. One of the most prominent factors that can influence these outcomes is the anatomical location or layer at which of the mesh is fixed [20].
Two different operative techniques are the most frequently used in case of ventral hernia; the onlay and the sub-lay repair techniques. However, it remains unclear which technique is superior.

In this study there was no statistical difference regarding age, gender and type of ventral hernia, whether de novo or incisional, between the two study groups $(\mathrm{p}=0.08,0.9,0.7$ respectively).

Initially, Considering the operative time, in our study, the mean operative time was longer in the sublay than the onlay techniques. The mean for the onlay repair operative time was $58.3 \pm 16.9$ minutes (range 40 to 90 mins) compared with $75.7 \pm 15.6$ minutes in the sublay repair group (range 55 to $110 \mathrm{mins}$ ).

In the current study, findings came in agreement with these reported studies as the operative time in the sublay group patients was notably longer than in the onlay one.

To illustrate, in a study conducted by Godara $R$ et al [22], came to the conclusion that the mean operative time for surgery was $49.35 \pm 8.29$ (3090) minutes in the onlay group compared to (63.15) \pm 15.0 (36-96) minutes in the sublay group $(\mathrm{p}<0.001)$. Furthermore, in a study by Saber A et al [23] found that the mean operative time for the onlay repair was $67.04 \pm 13.19$ minutes ranged from 45 to 90 minutes while in the sublay group was $93.26 \pm 24.94$ minutes ranged from 60 to 140 minutes $(\mathrm{P} \leq 0.0001)$. Ultimarely, Raghuveer M. N. et al [8]. stated that the mean total time taken for the operation in the sublay group was $72.3 \pm 9.23$ minutes, compared to $65.25 \pm 10.58$ minutes in the onlay group; and was found to be statistically significant $(\mathrm{p}<0.05)$.

The difference of time can be accounted due to more dissection time needed for creating retromuscular space. Securing reasonable hemostasis is another burden on time. Ease of operation is largely subjective and depends on 
individual surgeon's experience, exposure and planning, quality and quantity of assistance, conductive facilities such as light, cautery, instruments quality and sutures etc. [8].

\section{Secondly, regarding the length of hospital stay,} the study showed that the mean duration of $2.3 \pm 0.8$ days in the sublay group versus $2.5 \pm 0.7$ days in the onlay one. That was statistically insignificant $(\mathrm{p}=0.6)$

Nonetheless, these findings are relatively concordant with Raghuveer M. N. et al [8], where the duration of the postoperative hospital stay in the sublay group was $4.8 \pm 1.51$ days, whereas it was $6.68 \pm 1.46$ days in the onlay group, which, in co was, contrastingly, statistically significant $(\mathrm{p}<0.05)$.

The idea is to encourage the patient for early ambulation and to avoid hospital acquired infection. Patients were allowed to be discharged with a suction drain in place to be removed while later during outpatient visits only in case of the patient capability of taking care of the surgical wound and the drain with recording the daily output.

Moreover, as regard to the surgical site infection, events in our study, there were 3 cases (20\%) in the onlay group with superficial SSI and one case $(6.7 \%)$ event of skin flap necrosis, which required later close follow up with frequent dressings, while there was only one case $(6.7 \%)$ of superficial SSI event in the other sublay repair group with no events of skin flap necrosis.

That was nearly the same as the study conducted by Raghuveer M. N. et al [8] which showed the incidence of surgical site infection seen developed more prominently in the onlay group (26\%) when compared to the sublay group (12\%) and more than that conducted by , Bessa S. S. et al [24] whereas Superficial SSI was encountered in 1 patient $(2.5 \%)$ in the sublay group compared to no patients in the onlay group $(\mathrm{p}=1.000)$. This was limited to skin and subcutaneous tissue.

The retromuscular plane is highly vascular and helps preventing infection, and if any infection occurs in the subcutaneous plane, it will not affect the mesh, as the mesh is retromuscular in a deeper plane [8].

Sublay repair allows for tissue integration from two load-bearing tissues from both sides; posterior rectus sheath and the anterior myo-fascial complex. In addition, sublay mesh placement protects the mesh from exposure to superficial wound complications, intra-abdominal adhesions, and contamination. In addition, the creation of devascularizing skin flaps is avoided. While onlay method allows for tissue ingrowth from two directions, the skin flaps are not loadbearing. Mesh placed in the onlay location is vulnerable to infection forcing the surgeon to create devascularizing skin flaps and leaving the mesh susceptible to superficial local wound complications [25].

On the other hand, seroma formation in patients treated with onlay repair occurred in 2 cases $(13.3 \%)$ against no one in the sublay group with seroma collection after removal of the drain. Seroma management necessitated needle aspiration under aseptic conditions and application of abdominal binders, that was not followed by recollection.

In a study by Godara et al [22] $15 \%$ of cases developed seroma after onlay repair which were the same finings when compared with the study of concern. However, there was a difference in results regarding the sublay repair which showed seroma formation in $22.5 \%$ of cases.

Results reported by Bessa S. S. et al [24] showed two patients $(5 \%)$ in the onlay group developed clinically detectable seroma following removal of the suction drain while there were no events detected in the other group. 
The incidences of seroma formation are highest following onlay procedures as during an onlay procedure, not only due to many blood vessels are transected during the required wide mobilization of subcutaneous tissue flaps, but also the insertion of foreign material temporarily establishes an effective barrier between the circulatory system of the subcutaneous tissues and that of the deeper parietal layers [24]. Besides, in the sublay repair, the retromuscular space is an already existing anatomical plane, requiring no further dissection, and the bare posterior surface of the of the rectus muscles is rich in lymphatics which is capable of absorbing any collecting seroma [26].

In relation to the hematoma formation, in the current study, there was only one case of rectus sheath haematoma in the sublay group (6.7\%) despite and no similar events in the onlay group with no significant statistical difference between the 2 groups.

In comparing to a study conducted by Gleysteen et al [27] there was a higher incidence of haematoma in the sublay repair group (14\%) in contrast to the onlay group (6.7\%). Another study, conducted by Venclauskas et al [28] showed no events of haematoma in both groups. That was managed with ultrasound image guide needle aspiration under aseptic condition with application of an abdominal binder and frequent follow up.

This might be explained by dissecting in a vascular plane as the retromuscular may

\section{CONCLUSION:}

In present study, it was observed that the operative time of the onlay method was less when compared to sublay method and was the statistically significantly.

On the other hand, post-operative complications like suture site infection, seroma, flap necrosis, wound dehiscence and mesh infection was less in the sublay group when compared to the onlay complicate bleeding which in turn may lead to haematoma formation or even a clog inside the tube drain, clinically it is uncommon to manifest as a swelling unless it reaches a sufficient size if compared to onlay seroma or haematoma collection.

Ultimately, considering the recurrence rates, there were no events of recurrence in neither group of the study of concern. Patients were followed up in outpatient clinic in 1,3- and 6-months basis after discharge.

Additionally, recurrence rate in Dhaigude B. D. et al [29] study was $1 \%$ with recurrence seen only in 1 patient of onlay group and none in sublay group. Patients were followed up on the 1st month, 3rd month and the 6th month.

However, In Raghuveer M. N. et al [8] study, the recurrence rate in sublay group was $4.35 \%$ compared to $8.51 \%$ in onlay group, which was statistically insignificant $(p>0.05)$. Follow up every three months for 24 months.

This may attribute to the shorter period of followup in our study. As previous studies have shown that $70-75 \%$ of recurrences develop within 2 years and $80-90 \%$ develop within 3 years [30]. Our follow-up period, therefore, is probably not sufficiently long; thus, it is recommended to advocate longer durations of follow-up in subsequent studies.

group but were found to be statistically insignificant in present study.

Both sublay and onlay mesh placement techniques for ventral hernia repairs in low-risk adults are safe, efficient and are associated with comparable complications. Additional studies are needed to determine the long term benefits of both approaches with respect to mesh infection rates 
and hernia recurrence rates, as well as the ideal mesh location for VHRs in higher-risk patients.

\section{REFERENCES}

[1] Bedewi, M. A., El-Sharkawy, M. S., Al Boukai, A. A. \& Al-Nakshabandi, N. Prevalence of adult paraumbilical hernia. Assessment by high-resolution sonography: A hospital-based study. Hernia (2012). doi:10.1007/s10029-011-0863-4

[2] Ahmad, M., Niaz, W. A., Hussain, A. \& Saeeduddin, A. Polypropylene mesh repair of incisional hernia. J. Coll. Physicians Surg. Pakistan (2003). doi:08.2003/JCPSP.440442

[3] De Vries Reilingh, T. S. et al. Autologous tissue repair of large abdominal wall defects. Br. J. Surg. (2007). doi:10.1002/bjs.5817

[4] Millikan, K. W. Incisional hernia repair. Surgical Clinics of North America (2003). doi:10.1016/S0039-6109(03)00129-4

[5] Breuing, K. et al. Incisional ventral hernias: Review of the literature and recommendations regarding the grading and technique of repair. Surgery (2010). doi:10.1016/j.surg.2010.01.008

[6] Timmermans, L. et al. Meta-analysis of sublay versus onlay mesh repair in incisional hernia surgery. American Journal of Surgery (2014). doi:10.1016/j.amjsurg.2013.08.030

[7] Ramirez, O. M., Ruas, E. \& Dellon, A. L. 'Component separation' Method for Closure of Abdominal-Wall Defects: An Anatomic and Clinical Study. Plast. Reconstr. Surg. (1990).

[8] N., R. M., Muralidhar, S., Shetty, H. \& V., V. Onlay versus sublay mesh repair for ventral hernia. Int. Surg. J. 5, 823 (2018).

[9] Stumpf, M. et al. The lateral incisional hernia: Anatomical considerations for a standardized retromuscular sublay repair. Hernia (2009). doi:10.1007/s10029-009-0479-0

[10] Burger, J. W. A., Lange, J. F., Halm, J. A., Kleinrensink, G. J. \& Jeekel, H. Incisional hernia: Early complication of abdominal surgery. World J. Surg. 29, 1608-1613 (2005).

[11] Fassiadis, N., Roidl, M., Hennig, M., South, L. M. \& Andrews, S. M. Randomized clinical trial of vertical or transverse laparotomy for abdominal aortic aneurysm repair. Br. J. Surg. (2005). doi:10.1002/bjs.5140

[12] Luján, J. A. et al. Laparoscopic gastric bypass in the treatment of morbid obesity: Preliminary results of a new technique. Surg. Endosc. Other Interv. Tech. (2002). doi:10.1007/s00464-0029035-z

[13] Anthony, T. et al. Factors affecting recurrence following incisional herniorrhaphy. World J. Surg. (2000). doi:10.1007/s002689910018

[14] zollinger Robert M, ellison christopher. zollinger's atlas of surgical operations. (2011).

[15] (Peshawar, M. A.-J. of P. M. I. \& 2011, undefined. Tension Free mesh Hernioplasty; a Review of 96 cases. jpmi.org.pk

[16] Dubay, D. A., Wang, X., Kuhn, M. A., Robson, M. C. \& Franz, M. G. The prevention of incisional hernia formation using a delayed-release polymer of basic fibroblast growth factor. Ann. Surg. (2004). doi:10.1097/01.sla.0000131576.12153.ab

[17] Burger, J. W. A., Halm, J. A., Wijsmuller, A. R., Raa, S. Ten \& Jeekel, J. Evaluation of new 
prosthetic meshes for ventral hernia repair. Surg. Endosc. Other Interv. Tech. (2006). doi:10.1007/s00464-005-0706-4

[18] Altom, L. K. et al. Outcomes of emergent incisional hernia repair. Am. Surg. (2011).

[19] Haskins, I. N., Amdur, R. L., Lin, P. P. \& Vaziri, K. The Use of Mesh in Emergent Ventral Hernia Repair: Effects on Early Patient Morbidity and Mortality. J. Gastrointest. Surg. (2016). doi:10.1007/s11605-016-3207-y

[20] Albino, F. P. et al. Does mesh location matter in abdominal wall reconstruction? A systematic review of the literature and a summary of recommendations. Plast. Reconstr. Surg. (2013). doi:10.1097/PRS.0b013e3182a4c393

[21] Kummerow Broman, K. et al. Hidden Morbidity of Ventral Hernia Repair with Mesh: As Concerning as Common Bile Duct Injury? in Journal of the American College of Surgeons (2017). doi:10.1016/j.jamcollsurg.2016.09.016

[22] Godara, R., Garg, P., Raj, H. \& Singla, S. L. Comparative evaluation of 'Sublay' versus 'Onlay' meshplasty in ventral hernias. Indian J Gastroenterol (2006). doi:10.18203/23492902.isj20175892

[23] Saber, A., Bayumi, E. K. \& Bayumi Onlay, E. K. Versus Sublay Mesh Repair for Ventral Hernia. J. Surgery. Spec. Issue Abdom. Surg. Towar. Best 4, 1-4 (2015).

[24] Bessa, S. S., El-Gendi, A. M., Ghazal, A. H. A. \& Al-Fayoumi, T. A. Comparison between the short-term results of onlay and sublay mesh placement in the management of uncomplicated para-umbilical hernia: a prospective randomized study. Hernia (2015). doi:10.1007/s10029013-1143-2

[25] Saber, A. Onlay versus Sublay Mesh Repair for Ventral Hernia. J. Surg. 4, 1 (2016).

[26] Saeed, N., Iqbal, S. A., Shaikh, B. A. \& Baqai, F. Comparison between on lay and sublay methods of mesh repair of incisional hernia. J. Postgrad. Med. Inst. (2014).

[27] Gleysteen, J. J. Mesh-reinforced ventral hernia repair: Preference for 2 techniques. Arch. Surg. (2009). doi:10.1001/archsurg.2009.118

[28] Venclauskas, L., Maleckas, A. \& Kiudelis, M. One-year follow-up after incisional hernia treatment: Results of a prospective randomized study. Hernia (2010). doi:10.1007/s10029010-0686-8

[29] Dhaigude, B. D. et al. Comparative evaluation of sublay versus onlay meshplasty in incisional and ventral hernias. Int. Surg. J. (2017). doi:10.18203/2349-2902.isj20175892

[30] Weber, G., Horvath, O. P., Wéber, G. \& Horváth, O. P. Results of ventral hernia repair: comparison of suture repair with mesh implantation (onlay vs sublay) using open and laparoscopic approach--prospective, randomized, multicenter study . Magy. sebészet (2002). 